\title{
CONSERVAÇÃO PÓS-COLHEITA DE MANGA 'TOMMY ATKINS' COM 1-METILCICLOPROPENO'
}

\author{
MARINÊS PEREIRA BOMFIM², GIUSEPPINA PACE PEREIRA LIMA ${ }^{3}$, ABEL REBOUÇAS SÃO \\ JOSÉ $^{4}$, FÁBIO VIANELLO ${ }^{5}$, LUCIANA MANOEL DE OLIVEIRA ${ }^{6}$
}

RESUMO - O presente estudo teve como objetivo avaliar a conservação pós-colheita de manga Tommy Atkins tratada com diferentes concentrações de 1-MCP, armazenada sob refrigeração. Os tratamentos foram compostos de diferentes concentrações de 1-MCP: 0; 100; 300 e 600 nL.L-1 ${ }^{1}$ sendo armazenados por 12 horas em câmaras isoladas vedadas à temperatura de $25^{\circ} \mathrm{C}$; após abertura da câmara, os frutos foram armazenados nas temperaturas de $25^{\circ} \mathrm{C}$ com $75 \pm 5 \%$ de UR e $10^{\circ} \mathrm{C}$ com $70 \pm 5 \%$ de UR, por 28 dias. O delineamento foi inteiramente casualizado, em esquema fatorial $4 \times 6 \times 2$. Foram utilizadas quatro repetições por tratamento, com cinco frutos por parcela. As variáveis analisadas foram: perda de massa, firmeza, vitamina $\mathrm{C}$, açúcares totais e redutores e carotenoides. Nas condições em que o experimento foi conduzido, pode-se concluir que: as aplicações em pós-colheita de 1-MCP em manga Tommy Atkins foi eficiente em retardar o metabolismo de maturação dos frutos; o 1-MCP associado à refrigeração foi eficiente em manter os frutos armazenados por 28 dias de vida útil; a concentração de $600 \mathrm{~nL} . \mathrm{L}^{-1}$ de 1 -MCP foi considerada a mais eficiente em retardar o amadurecimento do fruto nas temperaturas de 10 e $25^{\circ} \mathrm{C}$.

Termos para indexação: Inibidores de etileno, vida útil, armazenamento.

\section{POST-HARVEST CONSERVATION OF 'TOMMY ATKINS' MANGOES TREATED WITH 1-METILCICLOPROPENO}

\begin{abstract}
The present study had the objective of evaluating the post-harvest conservation of 'Tommy Atkins' mangoes, treated with different concentrations of 1-MCP, stored under refrigeration. The treatments were several concentrations of 1-MCP, $0,100,300$ and $600 \mathrm{~nL} \mathrm{~L}^{-1}$, for 12 hours in isolated chambers at temperature of $25^{\circ} \mathrm{C}$. After opening the chambers, fruits were stored at temperatures of $25^{\circ} \mathrm{C}, 75 \pm 5 \%$ of $\mathrm{RH}$ and $10^{\circ} \mathrm{C}, 70 \pm 5 \%$ of $\mathrm{RH}$ for 28 days. The experimental design was a completely randomized in a factorial $4 \times 6 \times 2$. Four repetitions were used per treatment, with five fruits per plot. The analyzed variables were the loss of mass, the firmness, the vitamin $\mathrm{C}$, the total and reducer sugars and the carotenoids contents. Under the conditions in which the experiment was carried out, it can be concluded that: post-harvest applications of 1-MCP on 'Tommy Atkins' mangoes were effective in reducing the physiological metabolism of fruits maturation; 1-MCP and refrigeration associated were effective in keeping fruits stored for 28 days after harvesting; the 1-MCP concentration of $600 \mathrm{~nL} \mathrm{~L}^{-1}$ was considered the most efficient in reducing the ripening of fruits at $10^{\circ} \mathrm{C}$ and $25^{\circ} \mathrm{C}$.
\end{abstract}

Index terms: Inhibitors of ethylene, shelf life, storage.

\footnotetext{
${ }^{1}$ Trabalho Sinfruit 155 - Simpósio Internacional de Fruticultura - Avanços na Fruticultura (17 a 21 Outubro)

${ }^{2}$ Doutora em Agronomia - Universidade Júlio de Mesquita Filho - UNESP - Botucatu, mpbfito@gmail.com;

${ }^{3}$ Doutora - Departamento Química e Bioquímica - IB/UNESP, Botucatu;

${ }^{4}$ Doutor - Departamento de Química Biológica - Padova - Itália;

${ }^{5}$ Doutor UESB/DFZ, Vitória da Conquista - BA;

${ }^{6}$ Pós-doutoranda, UNESP-IB- Botucatu.
} 


\section{INTRODUÇÃO}

Dentre os vários fatores que prejudicam o aumento da exportação de manga, estão aqueles relacionados à sua alta perecibilidade, inviabilizando a competitividade do produto brasileiro no exterior. Para satisfazer esse ponto, os importadores exigem que esses frutos cheguem aos seus destinos com a máxima vida útil possível, o que obriga os exportadores, nas remessas por via aérea, a efetuarem ao longo da semana múltiplos embarques de pequenas quantidades para seus clientes (MARQUES; NOGUEIRA, 2000), elevando substancialmente o custo final do produto.

Entre as modernas técnicas aplicadas na póscolheita de frutos, está a aplicação de inibidores de etileno que promovem retardo na maturação, fator importante para o aumento do prazo de comercialização. Dos inibidores de etileno utilizados atualmente, destaca-se o 1-metilciclopropeno (1-MCP), composto gasoso que inibe a percepção de etileno por ligar-se de maneira irreversível à proteína receptora do etileno (SISLER et al., 1996), reduzindo severamente as mudanças associadas ao amadurecimento.

Este composto tem sido aplicado com sucesso em alguns frutos climatérios, tais como banana (GOLDING et al., 1998), maçã (FAN et al., 1999), damascos (FAN et al., 2000), inibindo a perda de firmeza dos frutos, retardando a mudança de cor, reduzindo a taxa respiratória e a produção de etileno, e proporcionando, portanto, aumento da vida útil pós-colheita.

O presente estudo teve como objetivo avaliar a conservação pós-colheita de manga Tommy Atkins tratada com diferentes concentrações de 1-metilciclopropeno (1-MCP), armazenada sob refrigeração e atmosfera modificada.

\section{MATERIAL E MÉTODOS}

O presente trabalho foi realizado na Universidade Estadual Paulista Julio de Mesquita Filho (UNESP), Câmpus de Botucatu. Os frutos de mangueira da cultivar Tommy Atkins foram colhidos no mês de janeiro de 2011, provenientes do pomar com sete anos de idade, da Fazenda Santa Maria, localizado no município de Taquaritinga, Estado de São Paulo (21'24'21' com latitude sul e 48 $30^{\circ}$ ' $18^{\prime \prime}$ ' de longitude W. Gr), com altitude de 565 metros, clima tropical de altitude com inverno moderado e seco, e verão quente e chuvoso, temperatura média anual de $24^{\circ} \mathrm{C}$ e precipitação pluviométrica de $1.600 \mathrm{~mm}$.

Os frutos foram submetidos aos tratamentos com 1- MCP (1-metilciclopropeno na formulação pó), Rohm e Haas Company Philadelphia EUA. Os tratamentos foram compostos com as concentrações de 1-MCP, T1- (controle), T2 - 100 nL.L- ${ }^{1}$; T3 - 300 nL.L- ${ }^{1}$ e T4 - 600 nL.L-1 ${ }^{1}$. Para a diluição do 1-MCP, foram utilizados frascos de vidro com septos nas tampas, nos quais foi colocado o produto, injetaram-se através dos septos, $25 \mathrm{~mL}$ de água à temperatura de $40^{\circ} \mathrm{C}$, agitando-se até a completa dissolução do Smartfres, obtendo-se 1-MCP gasoso. Os frascos contendo as diferentes concentrações de 1-MCP foram colocados dentro das caixas, e as tampas dos frascos retiradas, as caixas foram imediatamente fechadas e mantidas em temperatura de $25^{\circ} \mathrm{C}$ por 12 horas. Após esse período, as caixas foram abertas, e os frutos divididos em dois lotes, sendo um colocado em câmara refrigerada a $10^{\circ} \mathrm{C}$ com umidade relativa de $70 \pm 5 \%$, e o outro lote colocado em sala climatizada a $25^{\circ} \mathrm{C}$, com umidade relativa de $75 \pm 5 \%$, controladas diariamente. Variáveis analisadas: perda de massa sendo determinada em balança semianalítica com precisão $\mathrm{de} \pm 0,01 \mathrm{~g}$. Os resultados foram expressos em perdas percentuais, utilizando-se da relação entre o peso em cada dia de avaliação e o peso inicial, seguindo a equação: \%PM $=((\mathrm{MI}-\mathrm{MF}) / \mathrm{MI}) * 100$ onde: \% $\mathrm{PM}=$ porcentagem de perda de massa parcial acumulada; $\mathrm{MI}=$ Massa inicial da amostra em um período determinado em g; MF = Massa final da amostra no período seguinte a MI em g. Para avaliação da firmeza, utilizou-se texturômetro, com profundidade de penetração de $2,0 \mathrm{~mm}$ e ponteiro TA 9/1.000. A leitura foi realizada nos frutos inteiros, tomando-se quatro medidas por fruto, em faces opostas, após a remoção de porções da casca. Os resultados obtidos foram expressos em Newton $(\mathrm{N})$. A determinação dos açúcares totais foi realizada pelo método do Fenol-Sulfúrico, segundo metodologia descrita por Dubois et al. (1956). Os dados de açúcares totais foram expressos de acordo com a construção da curva-padrão de glicose anidra na concentração de $200 \mu \mathrm{g}-\mathrm{mL}^{-1}$. Para a determinação de vitamina $\mathrm{C}$, utilizou-se a metodologia de Terada et al. (1978). Os resultados foram comparados com a curva-padrão de ácido ascórbico $100 \mu \mathrm{g}-\mathrm{mL}^{-1}$ em ácido oxálico $0,5 \%$. A extração dos carotenoides totais foi realizada na matéria fresca, segundo o método validado por Sims e Gamon (2002). As leituras foram realizadas na região do visível a 663 (clorofila a), 647 (clorofila b), 537 (antocianina) e 470 (carotenoides) $\mathrm{nm}$. Os valores de absorbância foram convertidos em $\mu \mathrm{g}$ de carotenoides totais. $\mathrm{g}^{-1}$. O delineamento experimental adotado foi inteiramente casualizado, em esquema fatorial 4 × 6 × 2 (concentrações de 1-MCP x tempo $\mathrm{x}$ temperaturas). Foram utilizadas quatro repetições por tratamento, com cinco frutos por repetição. 


\section{RESULTADOS E DISCUSSÃO}

Dentre os resultados obtidos, observou-se que houve efeito significativo entre os fatores estudados em relação à perda de massa, havendo aumento de perda significativo ao longo do armazenamento. Provavelmente, a perda de massa foi influenciada pelos fatores tempo de armazenamento e concentrações de 1-MCP (Figura I). Menor perda de massa pode representar redução de perdas no volume comercializado, uma vez que se utiliza a massa como referência nas operações de venda.

A perda de massa com a concentração de 600 $n L . L^{-1}$ de 1-MCP mostrou-se menor em relação às demais concentrações a $25^{\circ} \mathrm{C}$. Já no armazenamento a $10^{\circ} \mathrm{C}$, os tratamentos com 1-MCP não diferiram entre si, mas diferiram da testemunha. De acordo com Doll Hojo (2005), as condições de armazenamento, determinadas pelas temperaturas e umidade relativa, interferem diretamente sobre o metabolismo da fruta, restringindo ou favorecendo a perda de água. Em manga Tommy Atkins tratadas com 1-MCP nas concentrações 30; 120 e 240 nL.L- ${ }^{1}$ e armazenadas a $12^{\circ} \mathrm{C}$ por 21 dias, Cocozza (2004) observou redução da perda de massa nos frutos tratados. Para todas as concentrações, o referido autor relatou que a perda de massa foi menor que o controle, sem diferenças estatísticas, havendo redução em perda de massa, em quase $10 \%$ em média, em relação aos frutos-controle. Os resultados encontrados no presente trabalho apresentaram semelhança em relação àqueles observados por Cocozza (2004). Outros trabalhos também descrevem a redução da perda de massa induzida pela aplicação de 1-MCP em manga Tommy Atkins. Lima et al. (2006) verificaram que concentrações de 600; 1.200 e 2.400 nL.L- ${ }^{1}$ reduziram a perda de massa em frutos acondicionados sob temperatura ambiente.

Para o fator firmeza, houve interação significativa, conforme pode ser observado na Figura 2, onde foi observado que o tratamento na concentração de 600 nL.L- ${ }^{1}$ promoveu menor diminuição da firmeza ao longo do período de avaliação. A firmeza da polpa é a variável mais avaliada nos trabalhos sobre a ação do 1-MCP em frutos. Neste estudo, a retenção da firmeza pelo 1-MCP foi observada no período entre o $14^{\circ}$ e o $21^{\circ}$ dia, registrando-se a maior diferença entre as concentrações ao $21^{\circ}$ dia, quando a concentração de $600 \mathrm{~nL} . \mathrm{L}^{-1}$ demonstrou ser a mais eficiente entre as concentrações estudadas, tanto para o armazenamento a $25^{\circ} \mathrm{C}$, como a $10^{\circ} \mathrm{C}$. Verificou-se que, ao longo do período de armazenamento, houve decréscimo na firmeza dos frutos de manga (Figuras 2A e 2B), como consequência do avanço do processo natural de amaciamento e senescência dos frutos. Assim, a aplicação de 1-MCP foi importante para a retenção da firmeza, pois frutos não tratados geralmente mostraram diminuição da firmeza mais acentuada. $\mathrm{O}$ atraso na perda de firmeza, resultante da ação do 1-MCP, é coerente com a hipótese de que o etileno desencadeia a atividade metabólica relacionada ao amaciamento (DONG et al., 2002; JEONG et al., 2002).

$\mathrm{O}$ teor de vitamina $\mathrm{C}$ nos frutos estudados foi influenciado pela aplicação do 1-MCP, observando tendência maior de retenção desse composto da maior para a menor concentração de 1-MCP (Figuras 3). Os teores de vitamina $\mathrm{C}$ variaram de 39 a $51,29 \mathrm{mg}$ de ácido ascórbico- $100 \mathrm{~g}^{-1}$ de polpa nos tratamentos-controle e $600{\mathrm{~nL} . L-{ }^{1}}^{1}$ de 1-MCP respectivamente, no armazenamento a $25^{\circ} \mathrm{C}$. Para o armazenamento a $10^{\circ} \mathrm{C}$, os teores de vitamina $\mathrm{C}$ variaram de $46,39 \mathrm{e}$ $69,34 \mathrm{mg}$ de ácido ascórbico- $100 \mathrm{~g}^{-1}$ de polpa para os tratamentos-controle e $600 \mathrm{~nL} . \mathrm{L}-{ }^{-1}$ de 1 -MCP, respectivamente (Figura 3A e 3B), semelhante ao observado para a outra temperatura estudada. Os tratamentos 300 e 600 nL.L- ${ }^{1}$ de 1-MCP diferiram significativamente dos demais tratamentos no período de avaliação e entre as temperaturas. Cocozza (2004), avaliando manga Tommy Atkins, notou que os teores de vitamina $\mathrm{C}$ foram maiores nos frutos sob efeito de 1-MCP, em relação à testemunha até os 20 dias de armazenamento refrigerado $\left(38,32 \mathrm{mg} .100 \mathrm{~g}-{ }^{1} \mathrm{polpa}\right)$, com destaque para a concentração de $100 \mathrm{~nL} \cdot \mathrm{L}^{-1}$. O mesmo autor também supôs que o fato do 1-MCP ter reduzido a produção de $\mathrm{CO}_{2}$ pode sinalizar um maior acúmulo de glicose utilizada na respiração do fruto, favorecendo a síntese do ácido ascórbico. Esses dados vêm corroborar os resultados obtidos no presente estudo também com manga Tommy Atkins, em que os frutos sob efeito do 1-MCP obtiveram maior teor de vitamina $\mathrm{C}$, diferindo da testemunha.

Para a interação entre os fatores estudados sobre os valores de açúcares solúveis totais e açúcares redutores, a análise de variância mostrou efeito significativo (Figuras 4A e 4B; 5A e 5B). Durante o período de armazenamento, notou-se aumento nos teores de açúcares solúveis totais em todos os tratamentos; entretanto, esse efeito foi mais acentuado nos frutos do tratamento-controle, em ambos os armazenamentos, indicando que, provavelmente, o metabolismo de degradação de amido foi mais acelerado do que nos frutos sob efeito do 1-MCP. Isto pode ser confirmado pelos resultados, comparando-se os frutos da concentração 600 nL.L- ${ }^{1}$, que apresentaram a menor porcentagem de açúcares solúveis totais no final de armazenamento $(7,58 \%$ e $6,84 \%)$, para os armazenamentos a $25^{\circ} \mathrm{C}$ e a $10^{\circ} \mathrm{C}$, respectivamente, em relação aos frutos do tratamento-controle, que 
apresentaram a maior porcentagem de açúcares solúveis totais $(11,38 \% 8,78 \%)$. O aumento de açúcares solúveis totais, geralmente, ocorre em frutos durante a fase de amadurecimento, como foi verificado em manga 'Amrapali' (SINGH et al., 1998) e manga Tommy Atkins (COCOZZA, 2003), independentemente dos tratamentos com 1-MCP. Bernardes Silva et al. (2004), avaliando a evolução dos açúcares solúveis durante o desenvolvimento e o amadurecimento de manga, notaram que as cultivares Tommy Atkins e Haden apresentaram o maior acúmulo, cerca de 12 e $10 \%$, enquanto as cultivares Van Dyke e Palmer foram as que menos acumularam, cerca de $7,30 \%$ e $9,79 \%$, respectivamente. No presente trabalho, o conteúdo dos açúcares redutores mostrou tendência de aumento ao longo do processo de amadurecimento, sendo observado maior teor no tratamento-controle no armazenamento a $25^{\circ} \mathrm{C}$, enquanto sob armazenamento a $10^{\circ} \mathrm{C}$, observou-se menor incremento dos açúcares redutores, nos frutos sob efeito do 1-MCP, nas concentrações de 300 e 600 nL.L-1 ${ }^{1} 1-\mathrm{MCP}$, indicando, possivelmente, menor hidrólise de amido (Figuras 5A e 5B). Os teores de açúcares em manga variam em função de cultivares, condições nutricionais do solo, condições climáticas, estágio de maturação e temperatura de armazenamento. Os principais açúcares presentes são a glicose, a frutose e a sacarose (BERNARDES SILVA, 2000). Neste trabalho, a ação do 1-MCP pode ter diminuído a atividade de enzimas hidrolíticas do amido, diminuindo, dessa forma, a concentração de açúcares. Isto pode ser observado nos teores de sólidos solúveis (Figuras 5). Segundo Blankenship e Dole (2003) e Watkins (2006), apenas alguns trabalhos registram efeitos do 1-MCP na conversão do amido em açúcares, mas os resultados podem variar entre espécies, cultivares, condições de crescimento e estágio de maturação. De acordo com Lima et al. (2006), pode ocorrer inibição pelo 1-MCP na conversão de amido em açúcares livres, o que teria promovido menores valores desses carboidratos em alguns tratamentos. O conteúdo de açúcares em bananas tratadas com 1-MCP, de acordo com Golding et al. (1998), também não mostrou alterações, não havendo, dessa forma, influência desse composto nos teores de carboidratos.

Houve interação significativa entre os fatores estudados para carotenoides. Ao longo do período experimental, os frutos do tratamento-controle apresentaram os maiores níveis de carotenoides no armazenamento a $25^{\circ} \mathrm{C}$, assim como a $10^{\circ} \mathrm{C}$ (Figuras 6A e 6B), seguido da concentração de 100 nL.L- ${ }^{1}$, diferindo dos frutos das concentrações de 300 e 600 nL.L- ${ }^{1}$, os quais não diferiram entre si. $\mathrm{O}$ maior teor de carotenoides no estágio maduro é justificado pela síntese destes pigmentos, que ocorre durante o seu amadurecimento, atingindo o valor máximo no fruto completamente maduro (TAIZ; ZEIGER, 2004), o que poderia explicar o aumento destes compostos em todos os frutos, de todos os tratamentos, ao longo do período de armazenamento. Para os frutos que não receberam aplicação do $1-\mathrm{MCP}$, foi observada maior concentração de carotenoides até o $14^{\circ}$ dia de avaliação, nos frutos armazenados a $25^{\circ} \mathrm{C}$ (Figura 6A). Após esta época, os conteúdos de carotenoides diminuíram em manga sob efeito das concentrações de 0 e 100 nL.L- $^{1}$; por outro lado, frutos das concentrações 300 e 600 nL.L- ${ }^{1}$ mostraram os conteúdos de carotenoides constantes até o $28^{\circ}$ dia de avaliação no armazenamento a $10^{\circ} \mathrm{C}$ (Figura 6B). Moretti et al. (2001), estudando tomates cv. Santa Clara, no estádio breaker, tratados com 1-MCP por 12 horas, em quatro diferentes concentrações $(0 ; 250 ; 500 \mathrm{e}$ $\left.1.000 \mathrm{~nL} . \mathrm{L}^{-1}\right)$, mantidos em condições ambientais por 2 dias e então armazenados em câmaras frias a $20 \pm 1^{\circ} \mathrm{C}$, UR de $85-95 \%$, observaram que os frutos do tratamento-controle, armazenados por 17 dias, mostraram incremento aproximadamente de 190\% de carotenoides totais do que os frutos tratados com 1.000 nL.L ${ }^{-1}$ de 1-MCP. Esses resultados vêm corroborar os do presente estudo, em que os frutos do tratamento controle obtiveram maiores níveis de carotenoides, provavelmente em função da redução das alterações fisiológicas de maturação na pós-colheita.

A concentração de 1-MCP, necessária para apresentar efeito no bloqueio da ação do etileno, varia conforme a espécie, cultivar e estádio de maturação, nas condições em que o trabalho foi desenvolvido; houve redução da perda de massa induzida pela aplicação de 1-MCP em manga Tommy Atkins, e essa redução da perda de massa pode ser justificada pela redução na atividade metabólica do fruto; a ação do 1-MCP também promoveu atraso na perda de firmeza, resultante da hipótese de que o etileno desencadeia a atividade metabólica relacionada ao amaciamento; já para os teores de vitamina $\mathrm{C}$, foram conservados os maiores teores nos frutos tratados com 1-MCP, os quais podem ser atribuídos à menor senescência induzida pelo produto.

A tendência dos menores teores de carboidratos totais, observados após a aplicação de 1-MCP, provavelmente, se deve ao efeito negativo que esse composto pode ter sobre a degradação do amido, já que age sobre o etileno, e menor elevação dos açúcares redutores para os frutos tratados com 1-MCP está relacionada à diminuição da atividade metabólica dos frutos tratados e indica que houve menor hidrólise de sacarose ao longo do armazenamento ou, ainda, 
a perda de água dos frutos pode ter contribuído para o aumento da concentração dos açúcares.

Constatou-se que quanto maior a concentra- ção do 1-MCP, maior foi o tempo para começar o incremento de pigmentos carotenoides.
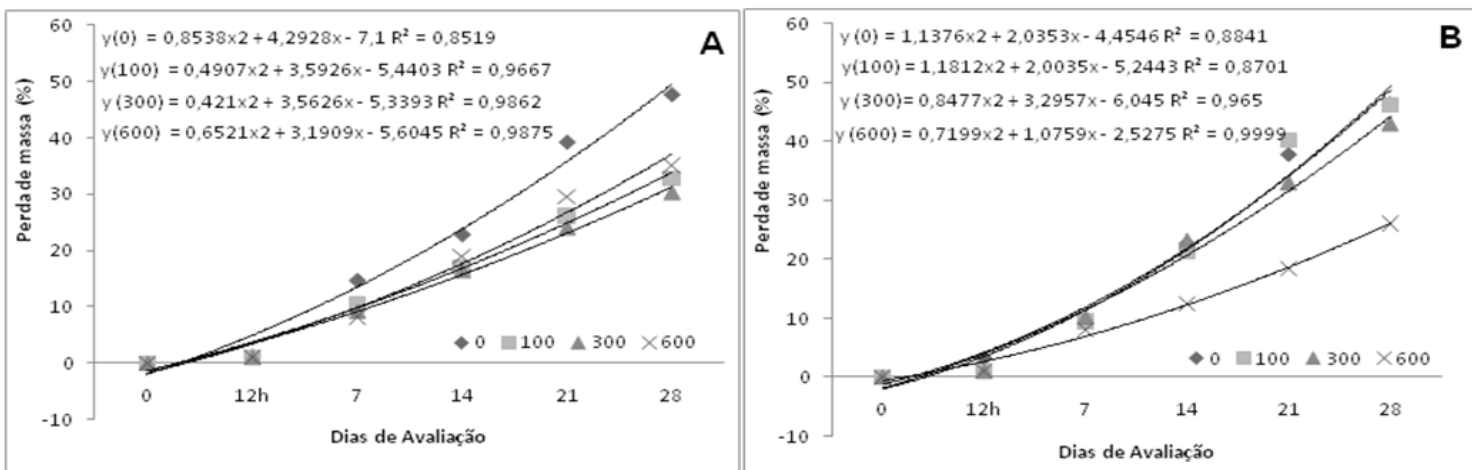

FIGURA 1 - Perda de massa (\%) em frutos de manga submetidos a diferentes concentrações de 1-MCP (A), armazenamento a $25^{\circ} \mathrm{C}$ e UR $75 \pm 5 \%$ (B), armazenamento a $10^{\circ} \mathrm{C}$ e UR $70 \pm 5 \%$, por 28 dias. Botucatu - SP, 2010.
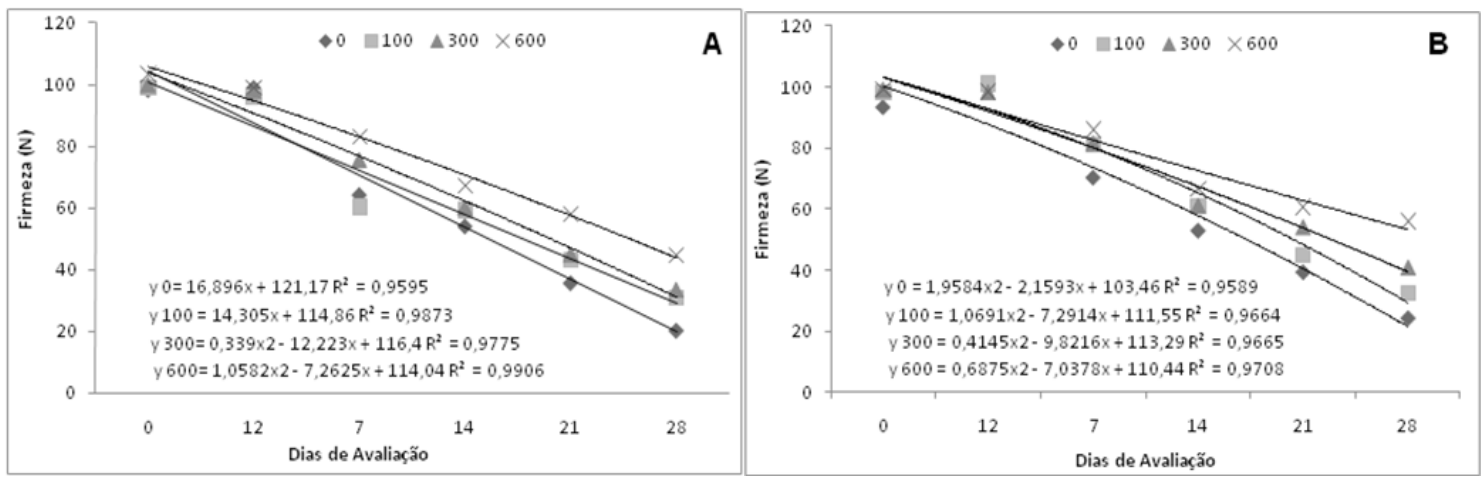

FIGURA 2 - Firmeza em $(\mathrm{N})$ em frutos de manga submetidos a diferentes concentrações de 1-MCP (A), armazenamento a $25^{\circ} \mathrm{C}$ e UR $75 \pm 5 \%$ (B), armazenamento a $10^{\circ} \mathrm{C}$ e UR $70 \pm 5 \%$, por 28 dias. Botucatu - SP, 2010.
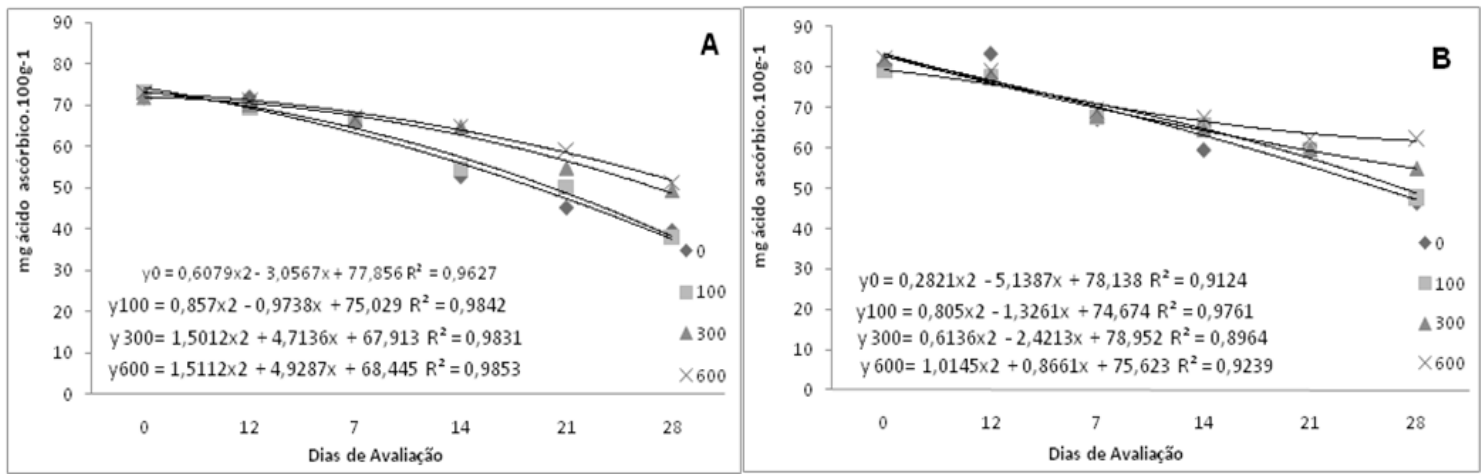

FIGURA 3 - Vitamina C (mg de ácido ascórbico.100 $\mathrm{g}^{-1}$ de peso fresco) em frutos de manga submetidos a diferentes concentrações de 1-MCP (A), armazenamento a $25^{\circ} \mathrm{C}$ e UR $75 \pm 5 \%$ (B), armazenamento a $10^{\circ} \mathrm{C}$ e UR $70 \pm 5 \%$, por 28 dias. Botucatu - SP, 2010. 

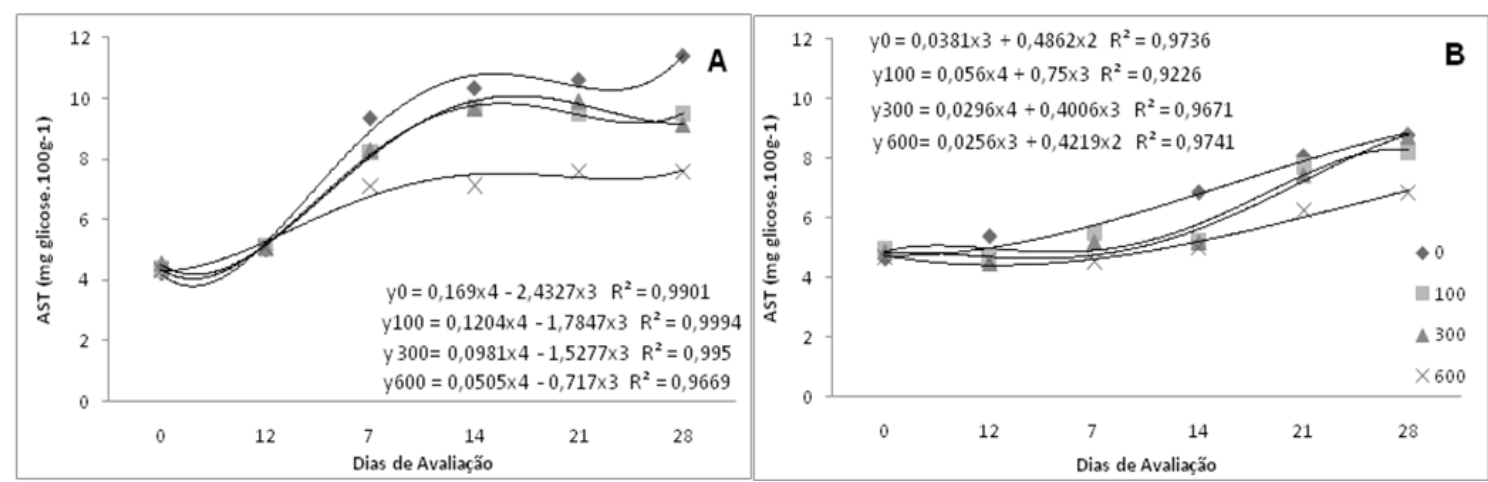

FIGURA 4 - Açúcares solúveis totais em frutos de manga submetidos a diferentes concentrações de 1-MCP (A), armazenamento a $25^{\circ} \mathrm{C}$ e UR $75 \pm 5 \%$ (B), armazenamento a $10^{\circ} \mathrm{C}$ e UR $70 \pm 5 \%$ por 28 dias. Botucatu - SP, 2010.
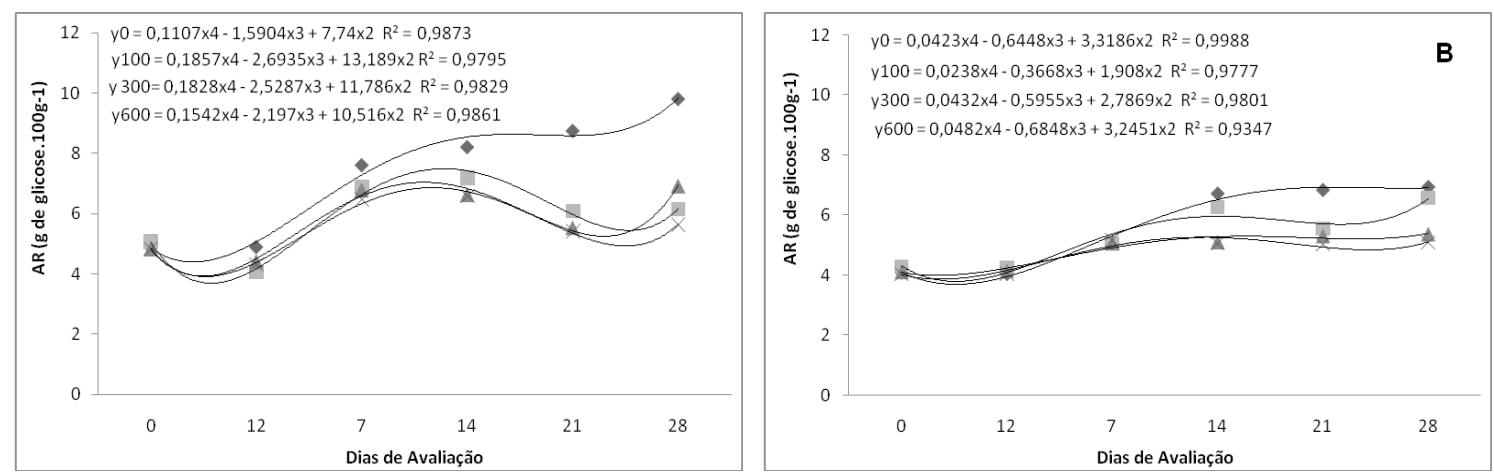

FIGURA 5 - Açúcares redutores (AR) em frutos de manga submetidos a diferentes concentrações de 1-MCP (A), armazenamento a $25^{\circ} \mathrm{C}$ e UR de $75 \pm 5 \%$ (B), armazenamento a $10^{\circ} \mathrm{C}$ e UR de $70 \pm 5 \%$, por 28 dias. Botucatu - SP, 2010

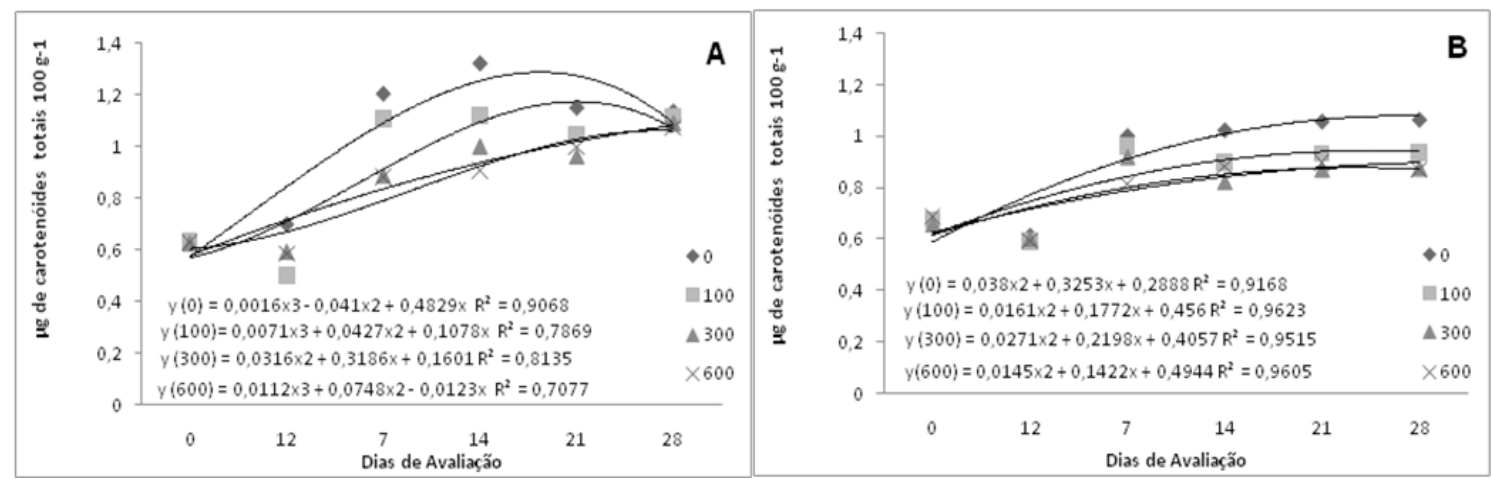

FIGURA 6 - Carotenoides totais em frutos de manga submetidos a diferentes concentrações de 1-MCP (A), armazenamento a $25^{\circ} \mathrm{C}$ e UR $75 \pm 5 \%$ (B), armazenamento a $10^{\circ} \mathrm{C}$ e UR $70 \pm 5 \%$, por 28 dias. Botucatu - SP, 2010. 


\section{CONCLUSÃO}

O 1- MCP foi eficiente em retardar o amadurecimento dos frutos em condições ambiente e sob refrigeração. A concentração de $600 \mathrm{~nL} \cdot$ L- $^{1}$ foi a mais eficiente em retardar o amadurecimento dos frutos nas duas temperaturas de armazenamento. $\mathrm{O}$ tratamento na concentração de $600 \mathrm{~nL} . \mathrm{L}^{-}{ }^{1}$, associado à refrigeração, foi eficiente em manter os frutos armazenados por 35 dias.

\section{AGRADECIMENTOS}

À Coordenação de Aperfeiçoamento de Pessoal de Nível Superior (CAPES), pela bolsa de Doutorado no Brasil e Exterior, e À Fundação de Amparo à Pesquisa do estado de São Paulo (FAPESP), pelo auxílio financeiro ao projeto de pesquisa.

À Fazenda Santa Maria, pela doação dos frutos de manga, e à Empresa AgroFresh Inc. - Rohm and Haas Química Ltda., pela doação do 1-MCP:

\section{REFERÊNCIAS}

BERNADES SILVA, A. P. F.; LAJOLO, F. M.; CORDENUNSI, B. R. Evolução dos teores de amido e açúcares solúveis durante o desenvolvimento e amadurecimento de diferentes cultivares de manga, Ciência e Tecnologia de Alimentos, Campinas, v. 23, n. 3, p. 116 - 120, dez. 2003.

BLANKENSHIP, S.; DOLE, J. M. 1-Methylcyclopropene: a review. Postharvest Biology and Technology, Amsterdam, v. 28, p. 1-25, 2003.

COCOZZA, F. del M.; PEREIRA, M. E. C.; ALVES, R. E. et al. Respiration rate and chemical characteristics of cold stored. Acta Horticulturae, Amsterdam, v. 645 , p. $645-650,2004$.

COCOZZA, F. del M. Maturação e conservação de manga Tommy Atkins à aplicação pós-colheita de 1-metilciclopropeno. 2003. 198 f. Tese (Doutorado em Tecnologia de Pós-Colheita) - Faculdade de Engenharia Agrícola, Universidade Estadual de Campinas, Campinas, 2003.

DOLL HOJO, E. T. Qualidade de mangas 'Palmer' tratadas com 1-metilciclopropeno e armazenadas sob refrigeração. 2005. 127f. Dissertação (Mestrado)- Universidade Federal de Lavras, Lavras, 2005.
DONG, L.; LURIE, S.; ZHOU, H.W. Effect of 1-methylcyclopropene on ripening of 'Canino' apricots and 'Royal Zee' plums. Postharvest Biology and Technology, Amsterdam, v.24, n.2, p.135-145, mar. 2002

DUBOIS, M.; GILLEWS, K. A.; HAMILTON, J. $\mathrm{K}$ et al. Colorimetric method for determination of sugar and related substances. Analytical Chemistry, Washington, v.28, n.3, p. 350-356, 1956.

FAN, X.; MATTHEIS, J. P. Yellowing of broccoli in storage is reduced by 1-methylcyclopene. HortScience, Alexandria, v.35, n.5, p.885-887, 2000.

FAN, X.; BLANKENSHIP, S. M. et al. 1-methylcyclopropene inhibits apple ripening. Journal of the American Society for Horticultural Science, Alexandria, v.124, n.6, p.690-695, 1999

GOLDING, J. B. et al. Application of 1-MCP and propylene to identify ethylene-dependent ripening processes in mature banana fruit. Postharvest Biology and Technology, Amsterdam, v.14, n.1, p. 87-98, Sept. 1998.

JACOMINO, A. P.; BASSETO, E. Efeito de 1- MCP e prochloraz na conservação de goiabas 'Pedro Satto'. Revista Iberoamericana de Tecnologia Postcosecha, Sonora, v. 4, n. 2, p. 122-127, 2002.

JEONG, J.; HUBER, D. J.; SARGENT, S. A. Influence of 1-methylcyclopropene (1-MCP) on ripening and cell wall matrix polygalacturonase of avocado (Persea americana) fruit. Postharvest Biology and Technology, Amsterdam, v. 25, n. 3, p. 241-256, 2002.

LIMA, M. A. C.; ALVES, R. E.; FILGUEIRAS, H. A. C. Mudanças relacionadas ao amaciamento da graviola durante a maturação pós-colheita. Pesquisa Agropecuária Brasileira, Brasília, v. 41, n. 12, p. 1707-1713, 2006.

LIMA, M. A. C. de; ALVES, R. E.; CUNHA, H. A. Uso de cera e 1-metilciclopropeno na conservação refrigerada de graviola (Annona muricata 1 .),

Revista Brasileira de Fruticultura, Jaboticabal, v. 26, n. 3, p. 433-437, 2004. 
MARQUES, M. C.; NOGUEIRA, J. M. Fruticultura: possibilidades de expansão e entraves no comércio internacional. Revista de Política Agrícola, Brasília, n. 3, p.24-39, 2000.

MORETTI, C. L.; MAROUELLI, W.A.; SILVA, W. L. C.; et al. Schedulling tomato fruit ripening with 1-methylcyclopropene. Proceedings of the Florida State Horticultural Society, Stuart, v.114, p. 118121, 2001.

SILVA, S.M.; SANTOS, E.C.; SANTOS, A.F. dos et al. Influence of 1-methylcyclopropene on postharvest conservation of exotic mango cultivars. Acta Horticulturae, Brugg, n.645, p.565-572, 2004.

SIMS, D. A.; GAMON, J. A. Relationship between pigment content and spectral reflectance across a wide range of species, leaf structures and developmental stages. Remote Sensing of Environment, New York, n.81, p. 337-354, 2002.

SINGH, S.; JHA, K.K. et al. Effect of calcium and polyethilene wrapping on storage life of mango. Indian Journal Horticultural, New Delhi, v.55, n.3, p.218-222, 1998.
SISLER, E.C.; BLANKENSHIP, S.M.; GUEST, M. Competition of cyclooctenes for ethylene binding and activity in plants. Plant Growth Regulation, Dortrech, v. 9, n.2, p.157-164, 1996.

TAIZ, L.; ZEIGER, E. Fisiologia vegetal. Porto Alegre: Artmed, 2004. 719 p.

TERADA, M.; WATANABE, Y.; KUNITOMA. et al. Differential rapid analysis of ascorbic acid and ascorbic acid 2-sulfate by dinitrophenilhydrazine method. Annals of Biochemistry, Calcutta, v. 84, p. 604-608, 1978.

WATKINS, C.B. The use of 1-methylcyclopropene (1-MCP) on fruits and vegetables. Biotechnology Advances, Amsterdam, v.24, n.4, p.389-409, july/ aug. 2006. 